\title{
Sickness absence and disability pension in relation to first childbirth and in nulliparous women according to occupational groups: a cohort study of 492,504 women in Sweden
}

Charlotte Björkenstam ${ }^{1}$, Krisztina D. László ${ }^{1,2^{*}}$ (D, Cecilia Orellana ${ }^{3}$, Ulrik Lidwall ${ }^{1,4}$, Petra Lindfors ${ }^{5}$, Margaretha Voss ${ }^{1}$, Pia Svedberg ${ }^{1}$ and Kristina Alexanderson ${ }^{1}$

\begin{abstract}
Background: Childbirth has been suggested to increase sickness absence (SA) and disability pension (DP). This may vary by occupation; however, knowledge in this field remains limited. We explored SA and DP in the years before and after childbirth among women in four occupational groups and those without occupation.

Methods: We studied nulliparous women aged 18-39years, living in Sweden on December 31, 2004 ( $n=492,504)$. Women were categorized into five skill-level based occupational groups and three childbirth groups; no childbirths within 3 years (B0), first childbirth in 2005 with no childbirth within 3 years (B1), and first childbirth in 2005 with at least one more birth within 3 years (B1+). We compared crude and standardized annual mean SA (in spells> 14 days) and DP net days in the 3 years before and 3 years after first childbirth date.
\end{abstract}

Results: Women in the highest skill level occupations and managers, had less mean SA/DP days during most study years than women in the lowest skill level occupations group. In B1 and B1+, absolute differences in mean SA/DP, particularly in SA, among occupational groups were highest during the year before childbirth. DP was most common in $\mathrm{B} 0$, regardless of group and year.

Conclusions: We found that women's mean SA/DP days before and after first childbirth was higher with decreasing skill-level of the occupational group and these differences were most pronounced in the year before childbirth. DP was most common among women not giving birth, regardless of occupational group.

Keywords: Sick leave, Child birth, Occupation, Disability pension

\footnotetext{
* Correspondence: krisztina.laszlo@ki.se

'Division of Insurance Medicine, Department of Clinical Neuroscience, Karolinska Institutet, Stockholm, Sweden

${ }^{2}$ Department of Global Public Health, Karolinska Institutet, Stockholm, Sweden

Full list of author information is available at the end of the article
}

(c) The Author(s). 2020 Open Access This article is licensed under a Creative Commons Attribution 4.0 International License, which permits use, sharing, adaptation, distribution and reproduction in any medium or format, as long as you give appropriate credit to the original author(s) and the source, provide a link to the Creative Commons licence, and indicate if changes were made. The images or other third party material in this article are included in the article's Creative Commons licence, unless indicated otherwise in a credit line to the material. If material is not included in the article's Creative Commons licence and your intended use is not permitted by statutory regulation or exceeds the permitted use, you will need to obtain permission directly from the copyright holder. To view a copy of this licence, visit http://creativecommons.org/licenses/by/4.0/ The Creative Commons Public Domain Dedication waiver (http://creativecommons.org/publicdomain/zero/1.0/) applies to the data made available in this article, unless otherwise stated in a credit line to the data. 


\section{Background}

Accumulating results suggest that women's sickness absence (SA) levels increase during pregnancy, both when compared to their levels before and after pregnancy, to their nulliparous counterparts, or to their partner's [110]. Some studies have suggested that women with children have higher SA than their nulliparous counterparts, prompting the load arising from the combination of paid and domestic work (the "double burden") as a possible explanation [3, 11, 12]. In contrast, other studies - including several of our own - suggest that, though pregnancy is associated with an increase in SA, women who give birth, especially those who give several births, have lower or comparable SA and lower disability pension (DP) levels in periods outside pregnancy than nulliparous women, even after considering demographic, socioeconomic or - through twin designs - genetic and familial environmental factors $[6,7,9,10,13,14]$; these suggest the existence of a health selection into childbirth and/or role enrichment, i.e., having multiple roles such as that of a parent and employee, may have also positive effects on health and SA [12].

It is well-documented in general working populations and in populations of reproductive age that low education, low occupational class, and low income are associated with markedly higher risks of SA [11, 15-18] and that work conditions contribute to the explanation of these associations $[19,20]$. A literature review on determinants of SA frequency, found that - besides the individual's health and lifestyle - sociodemographic factors and the physical and psychosocial characteristics of the workplace are important determinants [21]. Compared to other dimensions of health, SA has been attributed more to the job level (the degree of autonomy and authority at work) within an occupation [22]. A German study observed a clear gradient in SA by job level even after considering other socioeconomic factors [23].

Similarly, women's high SA during pregnancy may not be explained only by pregnancy-related medical conditions [9]. A Swedish study, investigating the role of work conditions in the relation between pregnancy and SA [24] concluded that levels of maternal SA appeared to be attributed also to non-medical factors, such as; attitudes towards work during pregnancy and latitude of SA criteria, i.e., if these also include common disorders associated with pregnancy that are otherwise not regarded as "illnesses". High physical and psychological job demands, limited possibilities to adjust the work conditions to the demands of the pregnancy, and positive attitudes towards sick listing may also contribute to pregnant women's SA [9]. Several of these factors vary by occupation, thus, it is plausible that SA/DP during pregnancy may vary according to occupational group. Similarly, women of high occupational groups may have better coping skills and more autonomy and more flexibility at their workplace, thus better possibilities to meet the challenges arising from combining paid work with pregnancy and with parenthood. A Swedish study analyzed whether the association between being registered to be living with children aged < 18 years and SA differs by education and income among women, but found limited support for such differences [11]. To our knowledge, no previous study has investigated whether the association between childbirth and SA/DP differs by occupational group.

In our recent Swedish study of initially nulliparous women we found that women who gave birth, especially those with several births, had generally lower mean SA/ DP days than women who did not give birth and that among parous women mean SA/DP increased mainly in the year before first childbirth and then decreased [9, 10]. In the present study we explored whether SA and DP trends in these three groups of women, i.e., those who remained nulliparous, who gave birth once, and who gave birth more than once during the study period, varied by their type of occupational group.

\section{Methods}

A longitudinal population-based cohort study of initially nulliparous women was conducted. We linked individuallevel information from five population-based registers by means of the unique personal identity number, assigned to all residents in Sweden [25].

The Longitudinal Integration Database for Health Insurance and Labor Market Studies (LISA), held by Statistics Sweden, was used to identify women who resided in Sweden on 31 December 2004. We further used this register to obtain information on occupation, country of birth, age, marital status, and year of immigration and emigration, respectively.

The Medical Birth Register (MBR), held by the National Board of Health and Welfare, was used to obtain information on childbirths (including stillbirths). The MBR covers 97-99\% of all births in Sweden since 1973 [26] and contains information on the mother's age, parity, the date of the child's birth, various maternal characteristics, and pregnancy outcomes. To identify childbirths not included in the MBR, we searched for childbirth-related diagnoses also in the National Patient Register (NPR), also held by the National Board of Health and Welfare; this register was established in 1964 and its coverage became nationwide in 1987 [27]. We obtained information on previous hospitalizations related to childbirth by searching among both primary and secondary diagnoses for the following International Classification of Disease (ICD) codes: ICD-7: 660, 670-678; ICD-8: 650-662; ICD-9: 650, 651, 652, 659X,W/659.W659.X, 669.E,F,G,H,W,X, and ICD-10: O75.7-O75.9, 
O80-84. If a childbirth appeared in both registers, we used the information from the MBR.

The Cause of Death Register held by the National Board of Health and Welfare was used to obtain information on date of death of the women included.

Finally, we obtained information from the register Micro Data for Analysis of Social Insurance (MiDAS), held by the Swedish Social Insurance Agency, on SA and DP (start and end dates and extent (full- or part-time)) during the years 2002-2009.

All residents in Sweden aged 16 years and older with income from work or unemployment benefits are entitled to SA benefits from the public sickness insurance system, if unable to work due to disease or injury. SA benefits are paid by the Social Insurance Agency, however, among employed individuals, sick pay is paid by the employer during the first 14 days of a SA spell. In order not to introduce bias regarding those unemployed, we only included SA spells $>14$ days. Most have a first qualifying day, and from the eight SA day a sickness certificate from a physician is required. DP can be granted to those aged 19-64 who, due to disease or injury, have permanently or long-term reduced work capacity, even if they have no previous income from work. Both SA and DP can be granted for full-time or part-time $(25,50 \%$ or $75 \%$ ) of ordinary working hours. Approximately $80 \%$ of the lost income, up to a certain limit, is covered by SA benefits, while up to $65 \%$ of lost income up to a certain limit, is covered by DP.

\section{Inclusion and exclusion criteria and formation of childbirth groups}

The LISA database was used to identify all women aged 18-39 years and living in Sweden on 31 December 2004 and who also had lived in Sweden during the three previous years (2002-2004). Using information on childbirths from 1964 (NPR) (1973 in MBR) through 2009, we created the following three childbirth groups $\left(\mathrm{T}_{0}=\right.$ date of childbirth):

- B1: Women having their first childbirth in 2005, and no childbirths during the three years and 43 weeks after $\mathrm{T}_{0}(N=14,299)$;

- B1+: Women having their first childbirth in 2005 and at least one more childbirth during the three years and 43 weeks after $\mathrm{T}_{0}(N=24,673)$;

- B0: Women with no childbirth registered neither before nor during the follow-up period (defined as 3 years and 43 weeks from 31 December 2005) $(N=$ 453,532).

Thus, women who gave birth to their first child in the 3 years and 43 weeks after 2005 and women who gave birth prior to 2005 were not included in the study. The additional 43 weeks in the above childbirth-group definition was to take into account SA or DP during a possible new pregnancy and to exclude those from the B0 group who were pregnant towards the end of the followup. A total of $556(1.43 \%)$ of the 38,972 women in B1 or $\mathrm{B} 1+$ were identified only through the NPR. For women who had their first childbirth during 2005, we set the date of delivery as $\mathrm{T}_{0}$. For women in $\mathrm{B} 0, \mathrm{~T}_{0}$ was set to 2 July 2005. The study period ranged from 3 years prior to 3 years after $T_{0}$.

\section{Occupation}

We obtained information on the women's occupation in 2004 from LISA. If this information was not available, data on occupation from 2005 was used to increase coverage on occupation. Occupation was coded according to the Swedish Standard Classification of Occupations 1996 (SSYK 1996) [28], which is based on the International Standard Classification of Occupations 1988. We used the first digit in the SSYK codes and categorized occupations into the following four groups and one additional group for the women without occupational information:

- Group 1: Legislators, senior officials, managers, and professionals (SSYK 0-2)

- Group 2: Technicians, associate professionals, and clerks (SSYK 3-4)

- Group 3: Service workers and shop sale workers (SSYK 5)

- Group 4: Skilled agricultural and fishery workers, craft and related trade workers, plant and machine operators, assemblers, and elementary occupations (SSYK 6-9)

- Group 5: No information on occupation.

\section{Sickness absence and disability pension days}

We calculated the number of annual mean net SA and DP days during each of the 3 years preceding $\mathrm{T}_{0}$ and the 3 years after for each group (See "Statistical analyses" section). Part-time SA/DP days were combined, e.g., two gross days of half-time SA or DP was counted as one net day.

\section{Sociodemographic factors}

We considered the following variables measured in 2004 from LISA [17]: age (categorized into four groups 1824, 25-29, 30-34, or 35-39 years), country of birth (four groups: Sweden, other Nordic country, other European Union 25, or rest of the world), type of living area (based on the H-classification scheme [29], categorized as: large city (Stockholm, Gothenburg, Malmö); medium-sized city ( $\geq 90.000$ inhabitants); or small city/village $(<90,000$ inhabitants), and family situation (married/cohabitant or 
single). Registration on cohabitation is not complete for couples without children, hence there is an underreporting of cohabitations for the years preceding childbirth, that is, in 2004.

\section{Analyses}

We first calculated for all occupational and childbirth groups the proportion of women with any SA/DP during the years studied. Since the great majority of women had no SA/DP days and thus the median in most of these groups was 0 days, we calculated mean SA/DP days in each of our occupational and childbirth groups; thus, though the continuous SA/DP days variable had a skewed distribution, we considered that the mean would be a more sensitive measure of the amount of SA/DP days than the median. We computed crude and standardized annual mean net SA and DP days with 95\% confidence intervals (CI), for the three childbirth groups within each of the five occupational groups, starting 3 years before $T_{0}$ and ending 3 years after $\mathrm{T}_{0}$. Study years are referred to as e.g., $\mathrm{Y}_{-3}$ (the third year before $T_{0}$ ), $Y_{+1}$ (the year after $T_{0}$ ). We used a direct standardization using $\mathrm{B} 1$ as the standard population. In the standardization, the following sociodemographic variables were taken into account; age, country of birth, type of living area, and family situation. Women who emigrated or died during the study years were excluded the year after emigration or death. All analyses were conducted using SAS 9.4.

\section{Results}

Of the 492,504 women included in this study, most were either in occupational group $3(31 \%)$ or in group 5 (no occupation, 26\%) (Table 1). The proportion of the three childbirth groups differed in the various occupational groups. No childbirth (B0) was most common in all five groups, spanning from $81.2 \%$ in occupational group 1 to $94.2 \%$ in occupational group 4 . In group $5,97.3 \%$ had no childbirth (B0). The highest proportion of $\mathrm{B} 1+$ was found in occupational group 1 (13.4\%) and lowest proportion in group $4(3.3 \%)$ and in group $5(1.3 \%)$. Women in group 5 were in general younger than those in the other groups. Regardless of occupational group, B0 women tended to be younger.

The number of SA/DP days/year ranged between 0 and 365/366. Overall, during all study years, SA/DP was most common in occupational group 4 (besides in group 5 , where especially DP was high), and was lowest in occupational group 1. Moreover, the absolute majority of the women had no SA or DP, regardless of occupational group or childbirth group (Table 2).

Table 1 Characteristics of women by occupational and childbirth groups $(N=492,504)$. Number and percentages

\begin{tabular}{|c|c|c|c|c|c|c|c|c|c|c|c|c|c|c|c|}
\hline \multirow[t]{2}{*}{ Factors, in December 2004} & \multicolumn{3}{|c|}{$\begin{array}{l}\text { Group 1: Non-manual } \\
\text { occupations } \\
\boldsymbol{n}=48,442(10 \%)\end{array}$} & \multicolumn{3}{|c|}{$\begin{array}{l}\text { Group 2: Lower non- } \\
\text { manual occupations } \\
\boldsymbol{n}=98,332(20 \%)\end{array}$} & \multicolumn{3}{|c|}{$\begin{array}{l}\text { Group 3: Manual } \\
\text { occupations } \\
\boldsymbol{n}=153,666 \text { (31\%) }\end{array}$} & \multicolumn{3}{|c|}{$\begin{array}{l}\text { Group 4: Lower } \\
\text { manual occupations } \\
\boldsymbol{n}=63,971 \text { (13\%) }\end{array}$} & \multicolumn{3}{|c|}{$\begin{array}{l}\text { Group 5: Missing } \\
\boldsymbol{n}=128,093(26 \%\end{array}$} \\
\hline & BO & B1 & $\mathrm{B} 1+$ & BO & B1 & $\mathrm{B} 1+$ & BO & B1 & $\mathrm{B} 1+$ & BO & B1 & $\mathrm{B} 1+$ & BO & B1 & $\mathrm{B} 1+$ \\
\hline Total \% & 81.2 & 5.4 & 13.4 & 87.9 & 4.0 & 8.1 & 93.0 & 2.8 & 4.2 & 94.2 & 2.5 & 3.3 & 97.3 & 1.4 & 1.3 \\
\hline \multicolumn{16}{|l|}{ Age (years) } \\
\hline $18-24$ & 13.0 & 2.1 & 2.0 & 36.7 & 9.9 & 9.9 & 64.0 & 35.6 & 38.7 & 61.8 & 35.2 & 39.6 & 73.6 & 62.6 & 62.9 \\
\hline $25-29$ & 33.9 & 28.2 & 41.1 & 29.5 & 36.9 & 47.9 & 20.0 & 36.3 & 42.3 & 17.6 & 33.6 & 39.9 & 11.7 & 16.2 & 18.2 \\
\hline $30-34$ & 29.8 & 46.3 & 48.1 & 18.6 & 35.8 & 35.4 & 8.9 & 20.3 & 16.6 & 10.1 & 21.0 & 17.0 & 7.7 & 14.3 & 14.4 \\
\hline $35-39$ & 23.3 & 23.4 & 8.8 & 15.2 & 17.5 & 6.9 & 7.0 & 7.9 & 2.4 & 10.5 & 10.2 & 3.5 & 7.0 & 6.9 & 4.5 \\
\hline \multicolumn{16}{|l|}{ Country of birth } \\
\hline Sweden & 89.5 & 91.0 & 94.4 & 91.4 & 91.0 & 94.3 & 89.4 & 86.7 & 90.6 & 87.1 & 83.3 & 88.9 & 82.4 & 73.6 & 73.7 \\
\hline Other Northern countries & 1.7 & 1.8 & 1.3 & 1.3 & 1.6 & 1.1 & 0.8 & 1.1 & 0.6 & 1.0 & 1.1 & 0.7 & 1.1 & 1.2 & 0.8 \\
\hline Other EU 25 & 2.6 & 1.8 & 1.2 & 1.3 & 1.6 & 0.9 & 1.0 & 0.8 & 0.7 & 1.3 & 2.0 & 0.9 & 2.4 & 1.9 & 1.8 \\
\hline Rest of the world & 6.2 & 5.4 & 3.2 & 6.0 & 5.7 & 3.7 & 8.8 & 11.3 & 8.1 & 10.6 & 13.6 & 9.5 & 14.1 & 23.3 & 23.7 \\
\hline \multicolumn{16}{|l|}{ Type of living area } \\
\hline Large cities & 55.4 & 55.9 & 56.5 & 51.7 & 49.4 & 47.8 & 41.3 & 37.1 & 33.3 & 35.8 & 33.6 & 28.9 & 40.0 & 39.4 & 38.9 \\
\hline Medium-sized cities & 30.8 & 29.4 & 29.7 & 32.4 & 31.9 & 33.6 & 36.6 & 36.4 & 38.0 & 39.5 & 35.0 & 37.1 & 36.7 & 36.5 & 35.5 \\
\hline Small cities & 13.8 & 14.7 & 13.8 & 16.0 & 18.8 & 18.6 & 22.1 & 26.6 & 28.7 & 24.7 & 31.3 & 34.0 & 23.3 & 24.1 & 25.6 \\
\hline \multicolumn{16}{|l|}{ Family situation } \\
\hline Married or cohabiting & 9.1 & 34.1 & 39.0 & 5.6 & 25.2 & 30.0 & 3.6 & 16.9 & 18.2 & 5.0 & 15.7 & 16.4 & 3.0 & 19.2 & 23.8 \\
\hline Single & 90.9 & 65.9 & 61.0 & 94.4 & 74.8 & 70.0 & 96.4 & 83.1 & 81.8 & 95.0 & 84.3 & 83.6 & 97.0 & 80.8 & 76.2 \\
\hline
\end{tabular}

All characteristics are obtained from LISA 2004. Occupation was obtained from LISA 2004, and if not available, from 2005

$B O$ No childbirth; $B 1$ one childbirth; $B 1+$ two or more childbirths 
Table 2 Number and proportion of women with sickness absence and/or disability pension during the years studied

\begin{tabular}{|c|c|c|c|c|c|c|c|c|c|c|c|c|c|c|c|c|}
\hline & & \multicolumn{3}{|c|}{ Occupation 1} & \multicolumn{3}{|c|}{ Occupation 2} & \multicolumn{3}{|c|}{ Occupation 3} & \multicolumn{3}{|c|}{ Occupation 4} & \multicolumn{3}{|c|}{ Group 5 missing } \\
\hline & & $\mathrm{N}$ & No SA/DP & SA/DP & $N$ & No SA/DP & SA/DP & $\mathrm{N}$ & No SA/DP & SA/DP & $\mathrm{N}$ & No SA/DP & SA/DP & $\mathrm{N}$ & No SA/DP & SA/DP \\
\hline \multirow[t]{3}{*}{$Y_{-3}$} & BO & 39320 & 92.1 & 7.9 & 86447 & 90.6 & 9.4 & 142865 & 92.0 & 8.0 & 60265 & 90.3 & 9.7 & 124635 & 88.3 & 11.7 \\
\hline & B1 & 2625 & 90.8 & 9.2 & 3896 & 88.1 & 11.9 & 4369 & 86.2 & 13.8 & 1608 & 83.1 & 16.9 & 1801 & 87.6 & 12.4 \\
\hline & B1+ & 6497 & 94.0 & 6.0 & 7989 & 91.8 & 8.2 & 6432 & 88.4 & 11.6 & 2098 & 86.8 & 13.2 & 1657 & 92.3 & 7.7 \\
\hline \multirow[t]{3}{*}{$\mathrm{Y}_{-2}$} & BO & 39320 & 92.2 & 7.8 & 86447 & 91.1 & 8.9 & 142865 & 92.3 & 7.7 & 60265 & 90.6 & 9.4 & 124635 & 87.6 & 12.4 \\
\hline & B1 & 2625 & 90.5 & 9.5 & 3896 & 87.8 & 12.2 & 4369 & 86.6 & 13.4 & 1608 & 84.8 & 15.2 & 1801 & 85.1 & 14.9 \\
\hline & B1+ & 6497 & 94.0 & 6.0 & 7989 & 92.3 & 7.7 & 6432 & 89.3 & 10.7 & 2098 & 87.1 & 12.9 & 1657 & 90.4 & 9.6 \\
\hline \multirow[t]{3}{*}{$Y_{-1}$} & BO & 39320 & 91.3 & 8.7 & 86447 & 90.3 & 9.7 & 142865 & 91.7 & 8.3 & 60265 & 89.7 & 10.3 & 124635 & 86.6 & 13.4 \\
\hline & B1 & 2625 & 65.6 & 34.4 & 3896 & 61.5 & 38.5 & 4369 & 60.5 & 39.5 & 1608 & 59.8 & 40.2 & 1801 & 77.7 & 22.3 \\
\hline & B1+ & 6497 & 74.0 & 26.0 & 7989 & 68.3 & 31.7 & 6432 & 64.8 & 35.2 & 2098 & 64.7 & 35.3 & 1657 & 80.8 & 19.2 \\
\hline \multirow[t]{3}{*}{$Y_{+1}$} & BO & 39320 & 90.6 & 9,4 & 86447 & 89.8 & 10.2 & 142865 & 90.8 & 9.2 & 60265 & 89,0 & 11.0 & 124635 & 85.4 & 14.6 \\
\hline & B1 & 2625 & 90.8 & 9.2 & 3896 & 89.3 & 10.7 & 4369 & 89.7 & 10.3 & 1608 & 89.6 & 10.4 & 1801 & 85.5 & 14.5 \\
\hline & B1+ & 6497 & 93.8 & 6.2 & 7989 & 93.3 & 6.7 & 6432 & 93.2 & 6.8 & 2098 & 92.3 & 7.7 & 1657 & 91.4 & 8.6 \\
\hline \multirow[t]{3}{*}{$Y_{+2}$} & BO & 38834 & 90.3 & 9.7 & 85822 & 89.5 & 10.5 & 142039 & 90.2 & 9.8 & 59890 & 88.4 & 11.6 & 122336 & 84.0 & 16.0 \\
\hline & B1 & 2619 & 92.7 & 7.3 & 3888 & 90.3 & 9.7 & 4366 & 88.5 & 11.5 & 1603 & 88.0 & 12.0 & 1794 & 85.2 & 14.8 \\
\hline & B1+ & 6496 & 87.1 & 12.9 & 7988 & 86.1 & 13.9 & 6432 & 81.9 & 18.1 & 2098 & 82.7 & 17.3 & 1657 & 85.6 & 14.4 \\
\hline \multirow[t]{3}{*}{$Y_{+3}$} & BO & 38251 & 90.8 & 9.2 & 85103 & 89.8 & 10.2 & 141106 & 90.1 & 9.9 & 59457 & 88.5 & 11.5 & 119403 & 83.0 & 17.0 \\
\hline & B1 & 2590 & 90.9 & 9.1 & 3866 & 88.7 & 11.3 & 4347 & 85.9 & 14.1 & 1597 & 86.7 & 13.3 & 1783 & 83.3 & 16.7 \\
\hline & B1+ & 6495 & 83.1 & 16.9 & 7987 & 81.2 & 18.8 & 6431 & 78.6 & 21.4 & 2098 & 79.6 & 20.4 & 1656 & 81.9 & 18.1 \\
\hline
\end{tabular}

$S A$ Sickness absence, $D P$ Disability pension, $B 0$ No childbirth, $B 1$ one childbirth, $B 1+$ two or more childbirths

When we analyzed crude mean SA days/year, we observed the lowest values in women in B1+ in occupational groups 1 and 2 during all years except at $\mathrm{Y}_{-1}$, and $\mathrm{Y}_{+3}$, when lowest mean SA days were found among women with no childbirths (B0) (Fig. 1). In occupational groups 3 and 4, women in B0 had the lowest mean SA days (7.9-9.4) during all years except during $Y_{+1}$, when women in B1+ had lowest SA net days (2.4 and 2.8, respectively). During the year of pregnancy $\left(\mathrm{Y}_{-1}\right)$, where the mean SA/DP days/year peaked, we saw a broad range of SA spanning from 20.0 days in occupational group 1 to 32.4 in group 4, among women in B1. DP, on the other hand, was most common in B0, regardless of occupational group and year studied. However, the mean values differed between occupational groups. In group B0 the annual mean DP days/year ranged from 1.2 to 4.8 in occupational group 1, from 2.1 to 7.0 in group 2, from 1.8 to 6.6 in group 3, and from 3.3 to 10.4 in group 4 . Highest mean DP days/year was seen in the group 5, ranging from 34.0 to 47.7 .

The standardized mean SA and DP days/year are displayed in Fig. 2. Also here, women in B1+ had lowest SA in occupation groups 1,2 , and 3 during all years except for $Y_{-1}$ and $Y_{+2}$ (group 1 and 3), $Y_{-1}$ and $Y_{+3}$ (group 2). During those years, women in B0 had lowest number of SA days. In occupation group 4, the B1+ group had lowest SA during $\mathrm{Y}_{-3}, \mathrm{Y}_{-2}$ and during $\mathrm{Y}_{+1}$ while B0 had lowest SA at $\mathrm{Y}_{-1}$. Regardless of occupational group and year, B1+ had lowest mean DP days/ year and B0 had highest. However, the mean DP days differed. B0 women in occupational group 1 had 0.9 mean DP days/year, as compared to 0.4 DP days in B1 and $0.5 \mathrm{DP}$ days in $\mathrm{B} 1+$ during $\mathrm{Y}_{-3}$. In occupational group 4, women in B0 had 5.6 mean DP days, in B1 they had 2.2, and in B1+1.0 mean DP days. The missing group (group 5) stands out regarding DP, during $\mathrm{Y}$ ${ }_{-3}$ the B0-women had 76.5 mean DP days, while those in B1 had 35.0, and those in B1+ had 20.5 mean DP days.

Also, from those figures it is clear that when measuring SA/DP in terms of length, rather than in terms of occurrence (as in Table 2), no group reached the highest possible number per year, i.e., 365 days or was even near that sum.

Figure 3 illustrates the levels of crude mean SA and DP net days/year combined and the corresponding confidence intervals, by the three childbirth and the five occupational groups. Overall, B1+ had fewest mean days. Among women who had at least one childbirth, all occupational groups had a peak at $\mathrm{Y}_{-1}$ followed by a decline.

\section{Discussion}

This large longitudinal cohort study of nulliparous women in Sweden in 2004, revealed that patterns of SA/ 


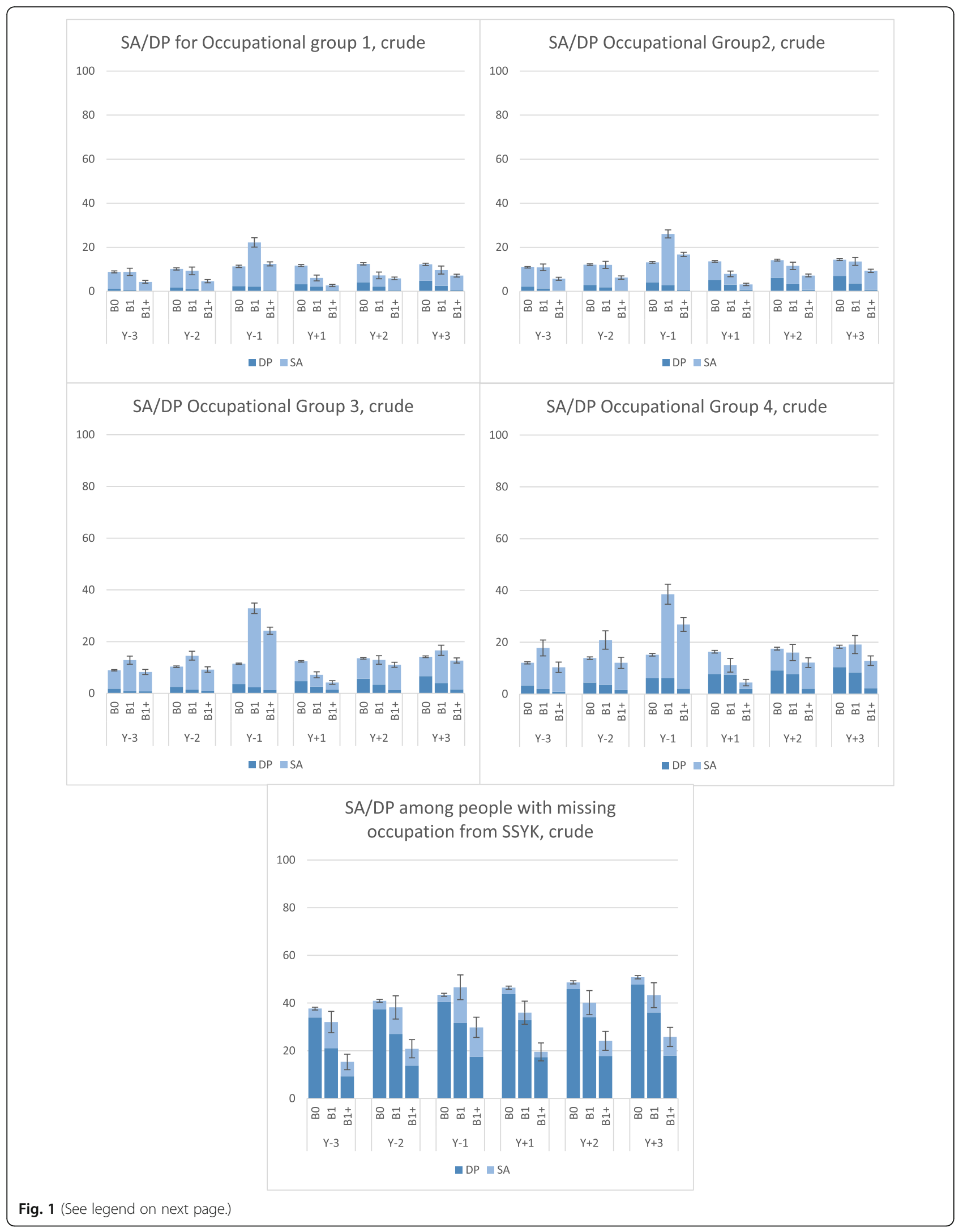


(See figure on previous page.)

Fig. 1 Annual crude mean sickness absence and disability pension days by occupational group, year and childbirth. SA, sickness absence; DP. disability pension; $Y_{-3}$ to $Y_{+3}$, the 3 years before and 3 years after date of birth/index date; Group 1-5, occupational group; B0, women with no childbirth neither before nor during the follow-up period (defined as 3 years and 43 weeks from 31 December 2005); B1, women having their first childbirth in 2005, and no childbirths during the 3 years and 43 weeks afterwards; B1+, women having their first childbirth in 2005 and at least one more childbirth during the 3 years and 43 weeks afterwards. The vertical lines represent the $95 \%$ confidence intervals for the sum of SA and DP net days

DP around the years of first childbirth varied according to occupational group, in a graded manner. Beside the group of women with no registered occupation (group 5), manual workers (group 4) had overall the highest mean SA/DP days in the periods immediately before and after pregnancy, and even more so during the time of pregnancy. In contrast, women in higher non-manual occupations (group 1), had the lowest overall mean SA/ DP days, including during the year before childbirth. The increase in SA during the year before childbirth was more pronounced with decreasing occupational group. Across most occupational groups, women who had more than one childbirth had the lowest mean SA/DP days, except during the year prior to first childbirth (i.e., when pregnant).

Our findings are in line with a large body of literature that has shown SA/DP to be more prevalent in occupations that require less education [16-18, 30-32] and with the few but increasing number of studies reporting that women who give birth, especially those with more than one birth (up to two or three during our study period), have except during pregnancy less or comparable SA/DP than their counterparts who do not give birth $[9,10,13,14]$, thus suggesting a health selection into giving birth, and especially for having more than one childbirth. In contrast to what has been suggested $[3,11,12]$, our findings suggest rather that childbirth is associated with less rather than more SA/DP, apart from during pregnancy.

Our study extends the findings of the previous studies investigating patterns of SA/DP in relation to childbirth by exploring differences across occupational groups in women's SA/DP in the years shortly before and after first childbirth, including during the period of pregnancy. Our finding that differences in the combined outcome SA/DP - and even more pronouncedly in SA across occupational groups increased during the year before pregnancy, i.e., when women were pregnant, and were smallest during the year after childbirth, i.e., when most mothers are on parental leave, highlights the possible contribution of the physical and the psychosocial work environment to SA/DP [17]. Prior studies have shown that high physical workload, high job strain, and low job control - work characteristics well-known to differ by occupational class - are associated with higher risks for SA and DP [17, 33-38]. Women in lower occupational groups may e.g., have more limited possibilities to adjust the work environment to the demands of the pregnancy, and may consequently have a higher risk of SA than women in higher occupational groups. Our findings are in line with results of a large Norwegian study, exploring 180,000 employed women, which suggested that the high number of SA days among young first-time pregnant women was due to a preponderance of working class women in this group, who generally have more SA [30].

Our results suggest that the group of women with no occupation have very high levels of combined SA/DP due to many women being on DP throughout the years and thus contributing much to high annual mean SA/ DP days. The fact that they to a higher degree were on DP, that is, having such a severe morbidity that it led to long-term or permanent work incapacity, might have affected both their capability to give birth and their decision to not give birth, suggesting a health selection into giving birth. The fact that these women also tended to be younger, might contribute to the fact they may have been too sick early on, to even enter the labor market or to continue their education. However, many of them also had SA, indicating income from work and/or unemployment benefits.

\section{Strengths and limitations}

The strengths of this study include its population-based and longitudinal design, the use of nationwide register data with high completeness and validity and virtually no drop-outs, the very large cohort, and that all women that fulfilled the inclusion criteria were included, not a sample $[25,27]$. Also, the use of NPR data in addition to the MBR allowed us to include childbirths not captured by the MBR. Furthermore, we were able to account for factors relating both to childbirth and occurrence of SA/ DP such as maternal age, country of birth, family situation, and type of living area, by means of a standardized analyses. Other strengths are that we could use net days instead of gross days, and that all information was based on administrative registers, not self-reports with possible recall bias. It is also an advantage that this study was conducted in a Swedish setting, with a very high employment rate among women - that is, the health selection into the labor market is not as strong as in other countries. However, this study also has some limitations that 


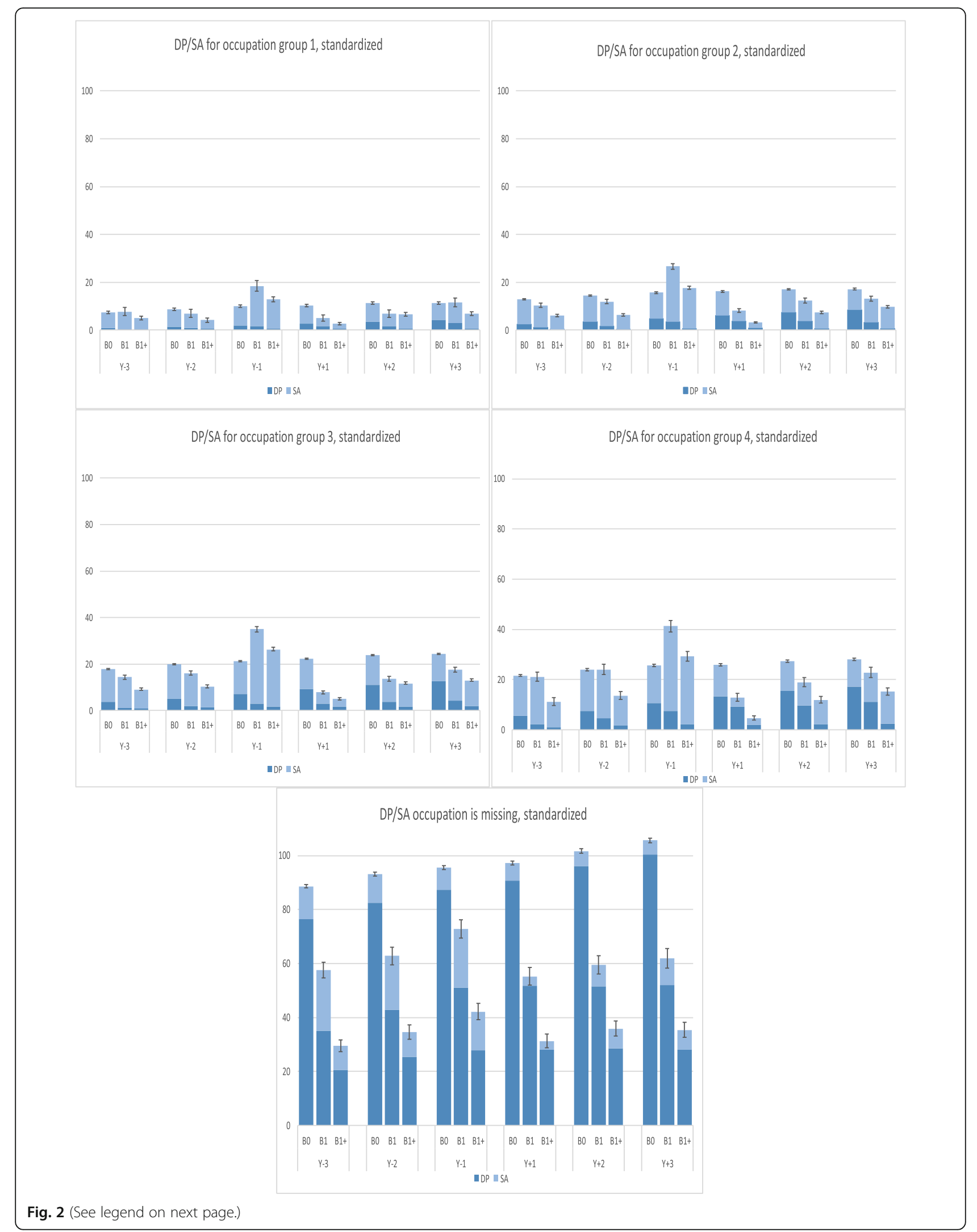


(See figure on previous page.)

Fig. 2 Annual standardized mean sickness absence and disability pension days by occupational group, year and childbirth. SA, sickness absence; DP, disability pension; $Y_{-3}$ to $Y_{+3}$, the 3 years before and 3 years after date of birth/index date; Group 1-5, occupational group; B0, women with no childbirth neither before nor during the follow-up period (defined as 3 years and 43 weeks from 31 December 2005); B1, women having their first childbirth in 2005, and no childbirths during the 3 years and 43 weeks afterwards; B1+, women having their first childbirth in 2005 and at least one more childbirth during the 3 years and 43 weeks afterwards. The vertical lines represent the $95 \%$ confidence intervals for the sum of SA and DP net days

need to be addressed. First, births among women who had only given birth outside of Sweden would not appear in the registers and these women might, therefore, be incorrectly categorized as B0, that is, as not having had any childbirths. This could lead to differential misclassification of exposure and thus biased levels of SA/ DP. To reduce this possible misclassification, and to make sure we had information on their possible SA/DP, we used residence in Sweden in 2002-2004 as an inclusion criteria. Second, the registers used in the analyses only hold data on SA reimbursed by the Swedish Social
Insurance Agency; thus SA spells $<15$ days were not included in our analyses. Although this means that the number of SA days per year is somewhat underestimated in all groups, it is not likely that the resulting misclassification of SA/DP would differ substantially by childbirth or occupational group. Moreover, the short SA spells account only for a limited number of the total number of SA days during a year [39]. Third, we did not have data on other aspects that might be associated with SA/DP, such as life style, morbidity, pregnancy symptoms, attitudes towards work and being on SA. Fourth, our

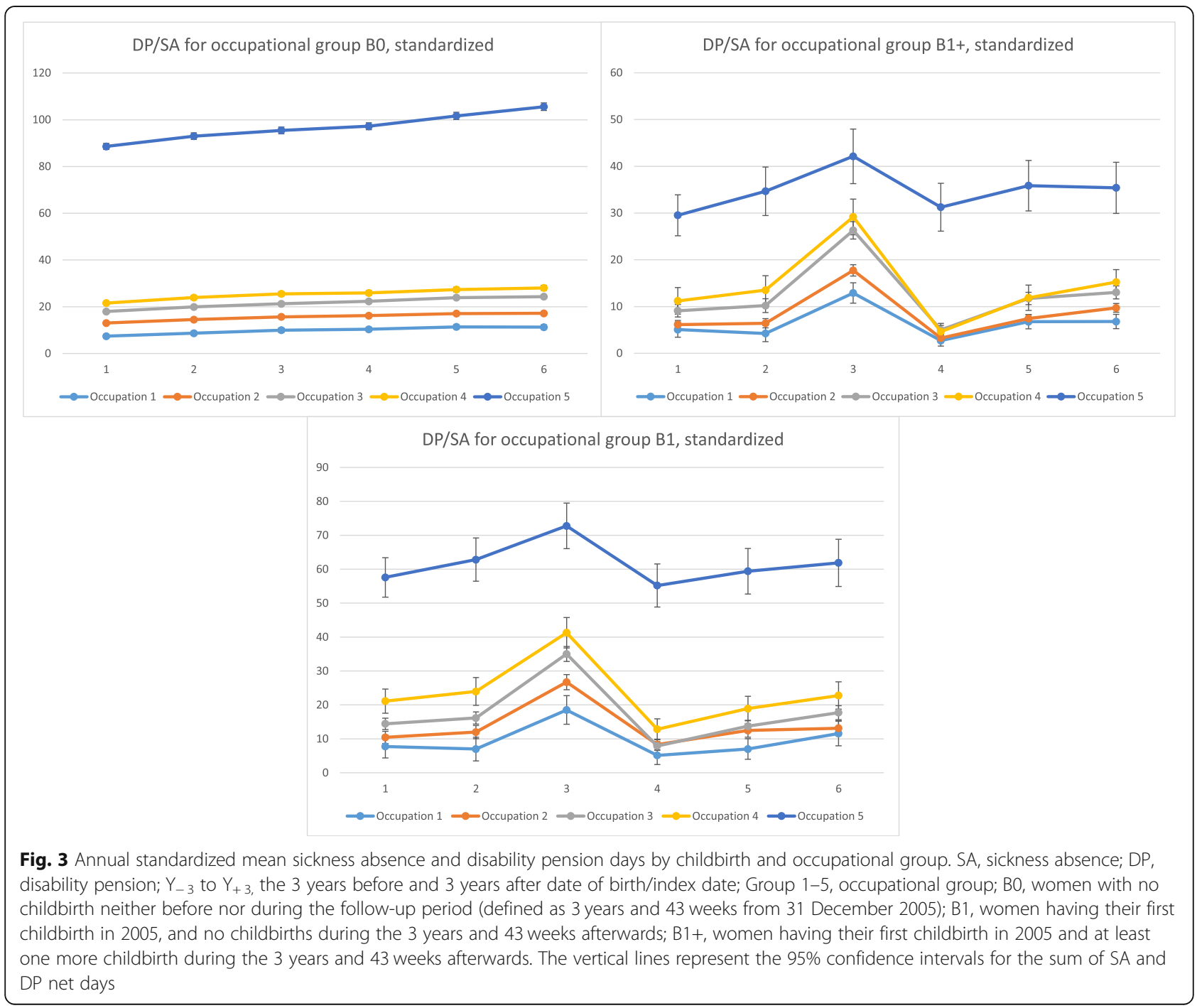


findings may be generalized only to countries with a high employment rate among women and with a welfare system comparable to that of Sweden in terms of universal provision of SA/DP and high-quality and almost free healthcare.

\section{Conclusions}

In conclusion, we found that trends in women's SA and DP in the years before and after first childbirth varied by occupational groups, and with having an occupation or not. The less education and skills needed in the occupation, the higher the number of mean SA/DP days in the period before and after childbirth, with this difference being most pronounced during the year before childbirth, i.e., during pregnancy. Mean SA/DP days were highest in the group of women with no occupation before giving birth.

\section{Abbreviations}

SA: Sickness absence; DP: Disability pension; BO: Women with no childbirth neither before nor during the follow-up period (defined as 3 years and 43 weeks from 31 December 2005); B1: Women having their first childbirth in 2005, and no childbirths during the three years and 43 weeks afterwards; $\mathrm{B} 1+$ : Women having their first childbirth in 2005 and at least one more childbirth during the three years and 43 weeks afterwards.; LISA: Longitudinal Integration Database for Health Insurance and Labor Market Studies; MBR: Medical Birth Register; NPR: National Patient Register; ICD: International Classification of Diseases; MiDAS: Micro Data for Analysis of Social Insurance; $T_{0}$ : Date of first childbirth or 2 July 2005; SSYK: Swedish Standard Classification of Occupations; Cl: Confidence intervals; $Y_{-3}$ : The third year before $T_{0} ; Y_{+1}$ : The year after $T_{0} ; Y_{-2}$ : The second year before $T_{0} ; Y_{-1}$ : The first year before $T_{0} ; Y_{+2}$ : The second after $T_{0} ; Y_{+3}$ : The third year after $T_{0}$.

\section{Acknowledgements}

Not applicable.

\section{Authors' contributions}

$\mathrm{CB}$ conducted the analyses, wrote the first draft, and revised the paper; $\mathrm{KL}$ contributed to writing, interpretation of the findings and revised the paper; $\mathrm{CO}$ contributed to analyses and revised the paper; UL, PL, and MV contributed to the design of the study, interpretation of the findings and revised the paper; PS and KA contributed to the conception and design of the study, interpretation of the findings, and revised the paper. Each author has read and approved the final version of the manuscript.

\section{Funding}

The study was supported by grants from the AFA Insurance Foundation (grant no.160318).

The funder had no role in the study design, in the collection, analysis or interpretation of the data, nor in the writing of the manuscript. Open access funding provided by Karolinska Institutet.

\section{Availability of data and materials}

The sensitive and confidential data used in this study cannot be made public according to the General Data Protection Regulation, the Swedish law SFS 2018:218, the Swedish Data Protection Act, the Swedish Ethical Review Act, and the Public Access to Information and Secrecy Act. Readers may contact Professor Kristina Alexanderson (kristina.alexanderson@ki.se) regarding the data.

\section{Ethics approval and consent to participate}

The project was approved by the Regional Ethical Review Board in Stockholm (Dnr. 2007/762-31; 2009/1917-32; 2012/863-32). Informed consent for participation in the study is not requested for register-based research.
Consent for publication

Not applicable.

\section{Competing interests}

The authors declare that they have no competing interests.

\section{Author details}

'Division of Insurance Medicine, Department of Clinical Neuroscience, Karolinska Institutet, Stockholm, Sweden. ${ }^{2}$ Department of Global Public Health, Karolinska Institutet, Stockholm, Sweden. ${ }^{3}$ Unit of Occupational Medicine, Institute of Environmental Medicine, Karolinska Institutet, Stockholm, Sweden. ${ }^{4}$ Department for Analysis and Forecast, Swedish Social Insurance Agency, Stockholm, Sweden. ${ }^{5}$ Department of Psychology, Stockholm University, Stockholm, Sweden.

Received: 27 January 2020 Accepted: 17 April 2020

Published online: 14 May 2020

\section{References}

1. Alexanderson K, Hensing G, Carstensen J, Bjurulf P. Pregnancy-related sickness absence among employed women. Scand J Work Environ Health. 1995;21:191-8.

2. Alexanderson K, Hensing G, Leijon M, Akerlind I, Rydh H, Carstensen J, Bjurulf P. Pregnancy related sickness absence in a Swedish county, 1985-87. J Epidemiol Community Health. 1994;48(5):464-70.

3. Angelov N, Johansson P, Lindahl E. Gender differences in sickness absence and the gender division of family responsibilities. Uppsala: Institute for Evaluation of Labour market and Education Policy (IFAU); 2013.

4. Mastekaasa A. Parenthood, gender and sickness absence. Soc Sci Med. 2000; 50(12):1827-42.

5. Vistnes JP. Gender differences in days lost from work due to illness. Ind Labor Relat Rev. 1997;50(2):304-23.

6. Björkenstam E, Alexanderson K, Narusyte J, Kjeldgard L, Ropponen A, Svedberg P. Childbirth, hospitalisation and sickness absence: a study of female twins. BMJ Open. 2015;5(1):e006033.

7. Brehmer L, Alexanderson K, Schytt E. Days of sick leave and inpatient care at the time of pregnancy and childbirth in relation to maternal age. Scand J Public Health. 2017:45(3):222-9.

8. Alexanderson K, Sydsjo A, Hensing G, Sydsjo G, Carstensen J. Impact of pregnancy on gender differences in sickness absence. Scand I Soc Med. 1996;24(3):169-76.

9. Laszlo KD, Bjorkenstam C, Svedberg P, Lindfors P, Alexanderson K. Sickness absence and disability pension before and after first childbirth and in nulliparous women by numerical gender segregation of occupations: a Swedish population-based longitudinal cohort study. PLoS One. 2019;14(12): e0226198.

10. Bjorkenstam C, Orellana C, Laszlo KD, Svedberg P, Voss M, Lidwall U, Lindfors $P$, Alexanderson K. Sickness absence and disability pension before and after first childbirth and in nulliparous women: longitudinal analyses of three cohorts in Sweden. BMJ Open. 2019;9(9):e031593.

11. Floderus B, Hagman M, Aronsson G, Marklund S, Wikman A. Medically certified sickness absence with insurance benefits in women with and without children. Eur J Pub Health. 2011;22(1):85-92.

12. The National Social Insurance Board: Social Insurance in Sweden 2004. In. https://www.forsakringskassan.se/wps/wcm/connect/af2fbe24-98ba-41d4b054-b0ca24022957/socialforsakringsboken_2004_eng.pdf? MOD=AJPERES; 2004. Accessed April 112020.

13. Björkenstam E, Narusyte J, Alexanderson K, Ropponen A, Kjeldgard L, Svedberg P. Associations between childbirth, hospitalization and disability pension: a cohort study of female twins. PLoS One. 2014;9(7):e101566.

14. Narusyte J, Björkenstam E, Alexanderson K, Ropponen A, Kjeldgard L, Svedberg P. Occurrence of sickness absence and disability pension in relation to childbirth: a 16-year follow-up study of 6323 Swedish twins. Scand J Public Health. 2016;44(1):98-105.

15. Marmot M, Bell R. Social inequalities in health: a proper concern of epidemiology. Ann Epidemiol. 2016;26(4):238-40.

16. Christensen KB, Labriola M, Lund T, Kivimaki M. Explaining the social gradient in long-term sickness absence: a prospective study of Danish employees. J Epidemiol Community Health. 2008;62(2):181-3. 
17. Allebeck P, Mastekaasa A. Swedish Council on Technology Assessment in Health Care (SBU). Chapter 5. Risk factors for sick leave - general studies. Scand J Public Health Suppl. 2004;63:49-108.

18. Lidwall U, Bill S, Palmer E, Olsson Bohlin C. Mental disorder sick leave in Sweden: a population study. Work. 2018;59(2):259-72.

19. Kaikkonen R, Harkanen T, Rahkonen O, Gould R, Koskinen S. Explaining educational differences in sickness absence: a population-based follow-up study. Scand J Work Environ Health. 2015;41(4):338-46.

20. Sterud T, Johannessen HA. Do work-related mechanical and psychosocial factors contribute to the social gradient in long-term sick leave: a prospective study of the general working population in Norway. Scand J Public Health. 2014;42(3):329-34.

21. Beemsterboer W, Stewart R, Groothoff J, Nijhuis F. A literature review on sick leave determinants (1984-2004). Int J Occup Med Environ Health. 2009;22(2): 169-79.

22. Beemsterboer W, Stewart R, Groothoff J, Nijhuis F. On regional differences in sick leave: the role of work, individual and health characteristics and sociocultural environment. Int J Occup Med Environ Health. 2008;21(4):345-61.

23. Kroger $H$. The stratifying role of job level for sickness absence and the moderating role of gender and occupational gender composition. Soc Sci Med. 2017;186:1-9.

24. Sydsjo A, Sydsjo G, Kjessler B. Sick leave and social benefits during pregnancy--a Swedish-Norwegian comparison. Acta Obstet Gynecol Scand. 1997;76(8):748-54

25. Ludvigsson JF, Almqvist C, Bonamy AK, Ljung R, Michaelsson K, Neovius M, Stephansson O, Ye W. Registers of the Swedish total population and their use in medical research. Eur J Epidemiol. 2016;31(2):125-36.

26. Cnattingius S, Ericson A, Gunnarskog J, Kallen B. A quality study of a medical birth registry. Scand J Soc Med. 1990;18(2):143-8.

27. Ludvigsson JF, Andersson E, Ekbom A, Feychting M, Kim JL, Reuterwall C, Heurgren M, Olausson PO. External review and validation of the Swedish national inpatient register. BMC Public Health. 2011;11:450.

28. Introduction SSYK 2012. In. www.scb.se; 2017. Accessed April 112020.

29. Rikets indelningar: Arsbok over regionala indelningar med koder, postadresser, telefonnummer m m. 2003 [Country classifications: Yearbook of regional classifications with codes, postal addresses, phone numbers, etc 2003] In Stockholm; 2003.

30. Ariansen AM. Age, occupational class and sickness absence during pregnancy: a retrospective analysis study of the Norwegian population registry. BMJ Open. 2014;4(5):e004381.

31. Corbett K, Gran JM, Kristensen P, Mehlum IS. Adult social position and sick leave: the mediating effect of physical workload. Scand J Work Environ Health. 2015;41(6):542-53.

32. Evans $\mathrm{O}$, Steptoe $\mathrm{A}$. The contribution of gender-role orientation, work factors and home stressors to psychological well-being and sickness absence in male- and female-dominated occupational groups. Soc Sci Med. 2002;54(4):481-92.

33. Jarvholm B, Stattin M, Robroek SJ, Janlert U, Karlsson B, Burdorf A. Heavy work and disability pension - a long term follow-up of Swedish construction workers. Scand J Work Environ Health. 2014;40(4):335-42.

34. Labriola M, Feveile $\mathrm{H}$, Christensen KB, Bultmann $U$, Lund T. The impact of job satisfaction on the risk of disability pension. A 15-year prospective study. Scand J Public Health. 2009;37(7):778-80.

35. Laine S, Gimeno D, Virtanen M, Oksanen T, Vahtera J, Elovainio M, Koskinen A, Pentti J, Kivimaki M. Job strain as a predictor of disability pension: the Finnish public sector study. J Epidemiol Community Health. 2009;63(1):24-30.

36. Krokstad S, Johnsen R, Westin S. Social determinants of disability pension: a 10-year follow-up of 62000 people in a Norwegian county population. Int J Epidemiol. 2002:31(6):1183-91.

37. Niedhammer I, Chastang JF, Sultan-Taieb H, Vermeylen G, Parent-Thirion A. Psychosocial work factors and sickness absence in 31 countries in Europe. Eur J Pub Health. 2013;23(4):622-9.

38. Norberg J, Alexanderson K, Framke E, Rugulies R, Farrants K. Job demands and control and sickness absence, disability pension and unemployment among 2,194,692 individuals in Sweden. Scand J Public Health. 2020;48(2): 125-33.

39. Hensing G, Alexanderson $K$, Allebeck P, Bjurulf P. How to measure sickness absence? Literature review and suggestion of five basic measures. Scand J Soc Med. 1998;26(2):133-44.

\section{Publisher's Note}

Springer Nature remains neutral with regard to jurisdictional claims in published maps and institutional affiliations.
Ready to submit your research? Choose BMC and benefit from:

- fast, convenient online submission

- thorough peer review by experienced researchers in your field

- rapid publication on acceptance

- support for research data, including large and complex data types

- gold Open Access which fosters wider collaboration and increased citations

- maximum visibility for your research: over $100 \mathrm{M}$ website views per year

At BMC, research is always in progress.

Learn more biomedcentral.com/submissions 